Richard Pfeilstetter

Heritage entrepreneurship. Agency-driven promotion of the Mediterranean diet in Spain.

This is the pre-copyedited author's final version of the journal article accepted for publication following peer review.

Original citation:

Pfeilstetter, R. (2015). Heritage entrepreneurship. Agency-driven promotion of the Mediterranean diet in Spain. International Journal of Heritage Studies 21 (3): 215-231.

The version of record is available online at:

https://doi.org/10.1080/13527258.2014.930502 


\title{
Heritage Entrepreneurship. Agency-driven promotion of the Mediterranean diet in Spain.
}

\author{
Richard Pfeilstetter ${ }^{\mathrm{a}}$ \\ ${ }^{a}$ Department of Social Anthropology, University of Seville, Spain
}

Received; accepted

This article explores the role of the agency in the social process that constitutes cultural heritage. By introducing the concept of heritage entrepreneurship to explain the conversion of cultural elements into heritage, we discuss the case of the Mediterranean diet (MD) in Spain. We explore the role of an expert NGO in the recent inclusion of the MD in the UNESCO Representative List of the Intangible Cultural Heritage of Humanity. Empirical evidence is presented for two basic patterns of heritage entrepreneurship, namely the construction and promotion of cultural heritage. First, we show how the community-heritage narrative is constructed in the official nomination file of the MD. Second, we analyze how businesses, governments and researchers constitute a specific heritage entrepreneur. We argue that the promotion of the MD as cultural heritage makes ordinary food different, both qualitatively (healthy and sustainable) and culturally (Mediterranean and traditional). We then look at the specific political, economic and scientific value of such a difference and its uses in Spain.

Keywords: Intangible Cultural Heritage; social anthropology; entrepreneurship; UNESCO; Mediterranean diet

\section{Introduction*}

*Email: rgp@us.es

Over the last decade, Intangible Cultural Heritage (ICH) has experienced a growing relevance as a field of research. Our paper contributes to this field, by discussing the case of the Mediterranean diet (MD) in Spain, recently put on the UNESCO Representative List of the ICH of Humanity (ICH List). We begin our article with a general outline of cultural heritage as part of the socio-cultural realm. This is illustrated by showing the economic, political and ideological implications of cultural heritage in contemporary Spain. It is argued that the reification of selected cultural elements by means of safeguarding policies need to be understood in a wider socio-cultural context of competition among different social agents for economic, social and cultural capital. 
In the second section, the theoretical framework of our paper is further reinforced. We establish the concept of heritage entrepreneurship and hold that it can accurately address the competitive, conflictive and agency-driven character of cultural heritage described in chapter one. In the third section, we present the case of the Mediterranean diet foundation (MDF), a non-governmental organization accredited to provide advisory services to the UNESCO committee. This institution coordinated the inscription process of the MD as an element on the ICH List. Applying our theoretical model, we show why the MDF can be understood as a heritage entrepreneur. The two following chapters provide empirical evidence of two basic patterns of heritage entrepreneurship, namely the construction and promotion of cultural heritage. First it is shown how the MD is constructed by the discursive reification of a community-heritage nexus. Evidence for this is provided from the official nomination file for the inclusion in the ICH List. Second, we explore how communities, business, politics and science relate to cultural heritage. By analyzing the institutional web that sustains the MDF we develop our understanding of how heritage entrepreneurship articulates different elites' interests over cultural heritage. In the last chapter we readdress the wider sociological sense of cultural heritage referred to at the beginning of the paper, now specifically focusing on the example of food in the Spanish context. The MD constructed and promoted as cultural heritage is now a distinctive kind of food, both qualitatively (healthy and sustainable) and culturally (Mediterranean and traditional). We show how this distinction is a catalyst, both for the quality food-related industries and research, and for those political and scientific practices using cultural differences as a resource. The conclusion discusses the scope of our contribution and summarizes some of the main arguments.

\section{Cultural heritage as a social, cultural and economic force in Spain}

[...] the significance of cultural heritage and its usages has been constituted principally from the influence of political ideology and practice, of the economic sector and of social sciences. (Zamora 2011, 104; translation by the author)

Cultural Heritage has multiple implications as a social, cultural and economic force within world society. Especially ICH is used as a criterion for distinguishing, comparing and unifying human beings principally in ethnic terms. The community-heritage connection is intrinsic and mutually legitimizing (Crooke 2010). The increase of values associated with the authentic, to local culture and identity as a reaction to globalizing tendencies of mobility, media and markets is directly related to the new forms of heritage construction (Kirshenblatt-Gimblett 2004, 58). An example of a recently constructed cultural heritage item is the MD, included in the ICH List for the first time in 2010 (UNESCO 2010b). The particularity of a cultural element, for example the MD, and the universality of the UNESCO category, representative heritage of humanity, universalizes particularities, and relates the global to the local. Legalizing, listing, 
protecting, describing, nameing and registering culture in terms of heritage is objectifying the intangible. A legal definition of a series of cultural values, products and places in terms of MD is an example of this. The definition and reification of selected cultural elements like the MD as $\mathrm{ICH}$ is then a catalyst for the constitution and evolution of social systems in the field of science, politics, and economics.

In the economic field, culture once processed as heritage, is a commodity. As the past is a scarce resource due to cultural constraints placed on it in the present (Appadurai 1981), it is suitable for economic exchange. Experiences, products and services can convert into traditional and authentic, and therefore desirable, so producing added value, when they relate to this scarce and exclusive inherited past. In Spain, tourism is one of the most important industries in the country. In 2012, about 12 per cent of all employed people worked in this sector (as of November 12, 2013, on the database of the Spanish Statistical Office). "Spain is still the second largest earner [from tourism] worldwide and the first in Europe (US\$ 56 billion), while ranking $4^{\text {th }}$ in the world by arrivals" (UNWTO 2013, 6). Cultural heritage has been introduced successively as a complement to what is the traditional marketing model of "sun and beach" to constitute a second resource for the leisure business. In this sense, some speak of an authenticityseeking model in the tourism industry in the twenty-first century (Wang 1999 or Zuckin 2008 for example). Specifically, cultural heritage as an economic-touristic resource is promoted in Spain through national and international policies. The Spanish Ministry of Industry, Energy and Tourism highlights on its website "Marcaespana" the importance of cultural tourism related to World Heritage Sites in Spain, since it is the second most ranked country in the world (as of December 9, 2013). The UNESCO Convention for the Safeguarding of Intangible Cultural Heritage (subsequently referred to as 2003 Convention) stresses "the importance of the intangible cultural heritage as [...] a guarantee of sustainable development" (UNESCO 2003). The European Union promotes both local cultural heritage construction and traditional food products as a specific rural development policy. "Tourism is a major growth sector in many rural areas and can build on cultural and natural heritage" (EU 2006, 27).

Cultural heritage is also an important variable in the Spanish political system. Contemporary Spain is characterized by strong ethno-political separatist/independence movements (choosing one word or the other may already be seen as a political statement). The most fundamental political issue in present-day Spanish society is whether in Spain there exists one or various nations, and if the latter is the case, whether these should constitute or not sovereign states. Different nationalist discourses, culturally justified, are related to political claims, like the regional distribution of state investment, the transfer of powers between regions and state or political sovereignty. Autonomous regions, namely Cataluña and the Basque Country, but also to a lesser extent other regions, as well as the state, the central government and a constitutional monarchy, are competing for legitimate authority by using different cultural identities and affiliations as a tool for political power. One way of doing so is by interfering in the construction of cultural elements as heritage items and in the interpretation of whom 
these elements represent. UNESCO's legal frameworks then work as an "international endorsement of national pride in heritage" (Prott 2009, 268). An evident example in contemporary Spain for the political implications of heritage is the bullfight, banned by the Catalonian government in 2012. Perceived outside Spain as typically Spanish the internal public discussion over whether or not it is a "good" or "bad" tradition indirectly puts a "good" or "bad" light on what Spanish and Catalonian culture generally is.

This particularly strong relevance of cultural heritage and $\mathrm{ICH}$ in the political and economic field in contemporary Spain also finds it refection in the proliferation of academic activity around the question of why something is typical, traditional and representative and for what kind of community it stands for. In this sense, Zamora relates patrimonial discourses in Spain to romanticism and ethnic nationalism reproduced by the intellectual elites $(2011,104-105)$. In particular, social anthropology has found in the ICH arena a field with strong professional possibilities in academia, politics and business. We argue that the explicit ethnic foundation of the ICH concept promoted by UNESCO is one of the main reasons for this. The 2003 Convention says that " $\mathrm{ICH}$, transmitted from generation to generation, is constantly recreated by communities $[\ldots]$ and provides them with a sense of identity and continuity" (article 2 point 1). As we are going to see later, the ethnic foundation of the MD as a transnational $\mathrm{ICH}$, gives raise to different community discourses. The Mediterranean people, the Mediterranean nations, for instance Spain and Catalonia, and Mediterranean communities, such as the Spanish region of Soria, appear to be supporters and transmitters of the Mediterranean diet.

\section{Heritage entrepreneurship}

As a theoretical framework for this paper, we understand cultural heritage as a social process (Hobsbawm and Ranger 1983, Harvey 2001, Smith 2006, Silverman 2011a). Cultural heritage is considered and appreciated by people as an especially meaningful cultural item for distinguishing collectives from one and another. Cultural items can become more or less heritage on a scale between irrelevant, that is not socially valued, human outcomes to heritage as main cultural imperative. We could speak of a scale of grades of authenticity. Cultural elements have succeeded on this scale, when they are declared legally as heritage by local, regional, national or international authorities. Cultural elements can cease to be considered heritage in the same way that they can start to be considered heritage. Specific heritage items are relative to time and space. For instance, in the past, the MD, was not considered to be a $\mathrm{ICH}$, there was no awareness of the distinctive character of this cultural element in relation to what is typical of certain communities. Conceptualizing heritage as a process raises the question of why potentially everything could be considered heritage but only a few things are considered to be heritage. Why the MD and not the Andalusian olive grove? How can this heritage process best be measured? Who are the key players in the heritage process? 
To address theoretically these questions we suggest a concept semantically related directly to processes of creating, defining, institutionalizing and exploiting ideas. In this line, an increasing number of scholars are using agency-based theoretical models to understand the implementation processes of cultural heritage. In November 2013 UNESCO promoted an international symposium discussing the role of ICH brokers, facilitators or mediators as a driving force for safeguarding heritage (unesco.org). At this event, Marc Jacobs spoke on cultural brokerage as a "keyword and critical success(f)actor" in safeguarding ICH. Kirshenblatt-Gimblett refers to heritage in terms of enterprise, an economy with proper actors $(2004,55,58,59,61)$. In this line of employing vocabulary from economic domains related to actor-based inquiry in the field of $\mathrm{ICH}$, our paper aims to discuss the advantages of linking the concept of entrepreneurship with heritage construction processes. Our approach is different from the idea of the mediator between the community and the experts or the distinction between heritage holders and heritage practitioners. Our notion of entrepreneurship focuses on institutionalized heritage construction and exploitation. The heritage entrepreneurs need to be identified empirically. They consist of emerging legally constituted institutions with the manifest or indirect goal of benefitting from ideas and discourses related to specific heritage items, both through production and exploitation of these ideas and discourses. This way, the anonymous entities like politics, community, heritage economy or UNESCO may be analytically domesticated and empirically targeted. The heritage process can be measured within all of these abstract entities in terms of key agencies or institutional driving forces.

Far from reducing entrepreneurship to the idea of a business creation on a micro-social level, we have developed an anthropological model of entrepreneurship inspired by the social theories of Pierre Bourdieu $(1972,1980)$ and Niklas Luhmann $(1984,1997)$. This model understands entrepreneurship as a process of social change fostered by the institutionalization of innovative and/or conflictive ideas in a social environment (Pfeilstetter 2011, 2012, 2013). The advantage of the entrepreneurship theorem in relation to the heritage process is its focus on the (1) agency insted of "anonymous forces", (2) on the legal institutionalization and (3) on the market-like competition for ecnomical, political and symbolical resources. This concept channels the emphasis of heritage research towards how emerging institutions articulate the specific interest of their stakeholders in relation to heritage elements. Creation, functioning and composition of institutions established to explore opportunities for economic and noneconomic profit from ICH become a central concern for inquiry. In this sense, we agree with De Bruin who suggests that heritage entrepreneurship consists of the "opportunities to acquire and/or safeguard customary, heritage-based resources" (2003, 170). However, we would like to amplify his notion. The opportunities in relation to ICH are connected to different types of benefits - economic, political, scientific, or religious, for example - and are articulated via specific emerging institutions. These can be companies, associations, social movements, political parties, specialized media, religious communities, departments within state-administrations at all levels, or NGOs. 
Our next section now introduces the specific case of an expert NGO as a heritage entrepreneur.

\section{The Mediterranean Diet Foundation}

The Association for the development of the Mediterranean diet is a union of Catalan food companies that founded the MDF in 1996 in order to "promote research on the MD in relation to its healthy, historical, cultural, culinary, agricultural and environmentally friendly aspects" and to safeguard the MD as a "ancient heritage common to the Mediterranean populations" (as of November 12, 2013, on the website of the MDF). Both the promotion of the idea of heritage as a capital, and therefore the moral and desirable value of the item, and the promotion of the community (the Mediterranean populations), can be seen as the core of the foundations objectives. The MDF is a nongovernmental organization accredited to provide advisory services to the UNESCO committee (UNESCO 2010a, 5). In this function, the MDF defines itself as a "nonprofit organization with a strictly cultural and scientific agenda" (MDF 2008, 4). The MDF is located in the Catalan capital Barcelona and technically coordinated the nomination process of the MD for the ICH List on behalf of the governments that initially promoted the inscription: Spain, Italy, Greece and Morocco (UNESCO 2010b). In December 2013, through a new resolution of the intergovernmental committee for the safeguarding of the ICH, Cyprus, Croatia and Portugal joined the initiative (UNESCO 2013). Consequently, this entity is a key actor in the legal consolidation of the MD as an item on the ICH List (subsequently referred to as ICH item of Humanity). We might say that the institution consolidated its role as a heritage entrepreneur once it brought the nomination process to a successful conclusion. On the other hand, the MDF was founded through private initiative and today is a platform linking different economic, political and scientific institutions to the MD.

We suggest that the MDF is a heritage entrepreneur, because it (1) successfully conducted the construction of an $\mathrm{ICH}$, now recognized internationally, through the technical coordination of the nomination process. (2) The MDF is a platform for the utilization of the MD by linking different stakeholders like communities, food businesses, governments, academic scholars to the heritage item. (3) The MDF has consolidated itself as a legalized institution, an accredited NGO, through the creation and use of an ICH item of Humanity. These dimensions of heritage entrepreneurship, construction, promotion and exploitation, are illustrated in the two following chapters. First, we analyze the nomination files presented for inscription on the ICH List in 2010 in Nairobi, Kenya, during the fifth session of the intergovernmental committee. The focus of our inquiry is on the implications of the heritage construction process in Spain. Theoretical arguments in the inscription file, the forms documenting the consent of the community and the ethnic justification of the element, are explored. We conduct a survey of political, economic and scientific discourses and the corresponding 
institutions articulated through the organizational chart of the MDF. The following observations are sustained empirically on a content analysis of UNESCO and MDF documents related to the MD. The focus on UNESCO's heritage denominations as an "arena [that] is dominated by written materials" (Brumann 2011, 19), and the discursive construction of heritage (Waterton, Smith and Campbell 2006) has motivated our research design. The methodological approach is associated with our theoretical groundwork: (1) the social construction of heritage, (2) heritage as capital, (3) the heritage-community relationship and finally, (4) the key role of emerging institutions which articulate the construction process.

\section{Discursive construction of the Mediterranean diet}

The most paradigmatic imposition of cultural elements as definitely appreciated and perceived as heritage is being on, what Kirshenblatt-Gimblett calls, The List (2004, 55). The ICH List "confer value on what is listed" (Kirshenblatt-Gimblett 2004, 55). From second world war until today "UNESCO became the foremost heritage authorizer" (Silverman 2011, 18). This international distinction certifies authenticity, prominence, moral integrity and uniqueness of certain cultural elements. A basic pattern of heritage entrepreneurship consists therefore of managing the successful creation of such brands that ensure further exponential growth in the symbolic, social and material value of the labeled item. One of the formal requirements for success on the ICH List is the building of a convincing community-heritage narrative. We now analyze why, and look at how the narrative was constituted for the case of the MD.

Looking at article 2 of the 2003 Convention, the ICH definition is related to (1) an anthropologically inspired concept of culture consisting of "practices, representations, expressions, knowledge, skills - as well as the instruments, objects, artifacts and cultural spaces associated therewith"; (2) secondly it has a constructivist character in the sense that the definition argues that heritage is what people recognize as their heritage: "[...] that communities, groups and, in some cases, individuals recognize as part of their cultural heritage." Finally, the definition is inspired by an (3) identity discourse: specific cultural elements recognized as heritage create a subjective (changing and related to the feeling of belonging) and objective (inherited, related to history and nature) criterion for distinguishing humans. "ICH [...] provides [communities] a sense of identity and continuity" (UNESCO 2003, Article 2). We can see the application of these three main criteria in nomination files for the inclusion of the MD in the ICH List:

a social practice based on the set of skills, knowledge, practices and traditions ranging from the landscape to the cuisine, which in the Mediterranean basin concern the crops, harvesting, fishing, conservation, processing, preparation and, particularly, consumption. This set, recreated within and by the communities identified in the territories of the four States Parties, is unavoidably linked to a 
seasonal calendar marked by nature and religious or ritual meanings. The MD as a unique lifestyle, determined by the climate and by the Mediterranean area, is also manifested through related festivals and celebrations. These events become the receptacle of gestures of mutual recognition, hospitality, neighbourliness, conviviality, intergenerational transmission and intercultural dialogue. This is how among these communities in particular, and the Mediterranean people in general, there is a feeling of rebuilding identity, of belonging, and of continuity, allowing them to recognize this element as an essential part of their shared intangible cultural heritage. (UNESCO 2010b, 4-5)

Adopting the UNESCO notion, the MD is promoted as culture in the widest sense of the term, a lifestyle related to all aspects of human life. From the moral point of view the nomination file relates it to a series of values: hospitality, neighborliness, conviviality, intergenerational transmission and intercultural dialogue. Finally, the promoters argue that it belongs to, and is recognized by, a specific collective: the Mediterranean people. UNESCO requires the candidates for admission in the ICH List to justify discursively, the cultural embeddedness of the element in a previously defined homogenous, for the purposes of the nomination file reified, ethnic group. For the praxis of heritage construction, this criterion makes it necessary for the promoters to imbed the Mediterranean people into a specific local community. For this purpose the promoters decided to defend the community of Soria for representing the Mediterranean people in Spain. The promoters of the nomination justify the selection of Soria as it follows:

The community of Soria has a population of 40,600 people (2008). Inhabited since the Bronze Age, Soria has acted as a crossroads - it is said that it is "the meeting town" -, and has nourished itself from the Mediterranean cultural mixing. The town, its landscapes and its monuments witness this while its cuisine and social interaction confirm it. To the northeast, Ágreda, "the town of the three cultures", recalls the co-existence on these high plains of the three Mediterranean monotheist religions: Hebrew, Christian and Muslim. Soria is the example of the inland territories and communities which are, however, still touched by the civilization of the Mediterranean and imbued with its culture. In fact, Cicero referred to continental people as homines maxime mediterranei ("the Most Mediterranean men"). Today, as in the past, the MD is always a major component of the identity of the members of this community. (UNESCO 2010b, 2)

As Soria is geographically located in the interior it is, as the promoters defend, an "example of the inland territories and communities which are, however, still touched by the civilization of the Mediterranean". Soria is "touched by" the civilization of the Mediterranean and "imbued with its culture". The MD is "always a major component" of their identity and "it is said that" Agreda is the town of three cultures. The references to landscapes and monuments, Cicero and the Bronze Age and to the small size of the community (forty thousand inhabitants) make up the discursive construction of a decidedly local community representing the MD. The intrinsic, essentialist and naturalized character of the community-heritage nexus throughout the discourse may be illustrated with statements such as "the town, its landscapes and its monuments witness this while its cuisine and social interaction confirm it". 
In addition to the definition of the community, there is a need for consent and collaboration with that community. The Operational Directives for the Implementation of the Convention for the Safeguarding of the ICH (2012) require the participation and consensus of the community. The represented community should participate actively in the construction of their own heritage. Therefore the nomination file of the MD includes documents signed by the leaders of local organizations containing their commitment to the UNESCO nomination. These include thirteen associations, three local businesses (for example, a door manufacturer), six municipalities, one local labor union, three schools, two chambers of commerce, five professional associations, two foundations and a university (UNESCO 2010b, 21-22). The common thread of these letters, all quite similar in form and content, is that they agree with the inscription, that their institution feels represented by the MD and that they commit to the safeguarding and transmission of the element.

As we have seen, heritage entrepreneurship discursively establishes, through the nomination file, a community and its consent in order to successfully put the MD on the ICH List. Once the cultural element is branded, heritage entrepreneurship opens up prospects of further uses of the newly created ICH item of Humanity, which the next section deals with.

\section{Economic, political and scientific promoters of the $\mathrm{MDF}^{2}$}

Promoting ICH on behalf of different interest groups is a possible business model, in the broadest sense, of heritage entrepreneurship. As UNESCO's "obligations on states to contribute assistance funding are optional" (Prott 2009, 271) and UNESCO encourages state parties to involve NGOs in the safeguarding of ICH items of Humanity (2003 Convention, article 9), a private engagement is likely. The institutional embeddedness of the MDF, the sponsorship, organizational chart, programs, projects and activities, reveal a diversity of economic, political and scientific stakeholders.

The board of the MDF can be divided into three groups: public, private, and semiprivate institutions (MDF 2008, 8). The list of political supporters consists of all three executive administrative spheres within the Spanish political system: nation-state government, regional government and local authorities. The Ministry of Agriculture, Food and Environment supports the foundation on behalf of the government. The government of Catalonia and the municipality of Barcelona complete the political support for the foundation that is classified by UNESCO as a non-governmental organization (UNESCO 2010a, 5).

On private business side, the foundation is supported by the Actel group which is made up of businesses and business organizations of the Catalan agro-industry sector: agricultural cooperatives, fruit and vegetable exporters, agro-insurance, fruit processing, 
etc. The Spanish arm of Danone, with its head office in Barcelona, commercializing dairy products and bottled water is the second supporter from the food business. The Catalan (sparkling) wine industry supports the foundation through the companies Freixenet and Miguel Torres. Finally, the company Gallina Blanca, a producer mainly of creams, soups, desserts and sauces, also directed from Barcelona, is the fifth food business supporting the MDF. All of these supporters are big players within the Spanish food sector, Danone and Freixenet within the top twenty in sales within their segments (as of December 12, 2013, on the website of the Spanish Federation of the Food and Beverage Industries). Together with the company Puratos - supplier of ingredients for the bakery, confectionery, ice-cream and catering industries - these companies also made up the Association for the development of the Mediterranean diet that once founded the MDF.

The third group of supporters, the public-private institutions, consist of Mercabarna, a publicly owned trading company in which Barcelona City Council is the majority shareholder. Mercabarna is a wholesale market for food products and provides the administration, distribution and logistics for buying and selling food in and around Barcelona. As of March 12, 2014, Mercabarna announces on its website their understanding of the mission of the MDF as a publicity maker for the regional food industry:

A foundation, promoted by companies in the agriculture and food industries around Spain, with the aim of encouraging the consumption of traditional produce from the Mediterranean region.

A second institution from this group is Prodeca, promoter of Catalan exports. The institution depends on the Catalonian Ministry of Agriculture, Fisheries and Environment. The company describes itself as a provider of "a series of services to Catalonia's food industry aimed at supporting foreign trade, and the internationalization and promotion of food quality" (Prodeca website, December 12, 2013). The relations and expected synergies between the promotion of Catalan food exports, nation-state building and the idea of Mediterranean cultural traditions becomes evident in the description of what Catalonia is on the web of Prodeca:

Catalonia is a modern country in Mediterranean Europe, that utilizes the most advanced technologies. It has a strong personality and loves its deeply-rooted customs and traditions. It is part of Spain and of the European Union. [...] It is an autonomous community within Spain, with its own government: the Generalitat of Catalonia. [...] It has therefore a strategic location, which has favoured, along history, an intense relationship with other Mediterranean countries and with continental Europe. [...] It is a good country to live in, as shown by the life expectancy of the Catalans, one of the highest in the world. The secret is a combination of favourable environmental conditions, good health coverage and a strong social safety net, a lifestyle that values hard work but finds time for leisure, and a gastronomy combining tradition, health and good taste. Catalans have always believed in work and they have distinguished themselves by their innovative capacity. This has made of Catalonia a country with strong foundations, a powerful 
civil society and an active work culture. Due to their high level of technical qualification and interpersonal skills, Catalans know how to respond in positive ways to the constantly evolving industrial and financial challenges of today's world.

This discourse linked to the item "Catalonia" on the internet page of Prodeca on December 12, 2013, is one of the six main nodes composing the headline of the web. The narrative links (1) culture elements, like ethnic self-distinction, tradition, taste, values, lifestyle with (2) economic elements, such as industrial challenges, innovative capacity, work culture and (3) political elements, for instance Catalonia as a country, its "strong foundations", self-government and reference to the Catalans in terms of society. The specific role of the Mediterranean as a claimed cultural space, positively-charged in terms of health, climate, gastronomy and good taste, may be appreciated in this example. The MD thus provides a persuasive argument both for food marketing and identity politics.

Turning to the role of scientific expertise within the MDF, we find lots of indications of academic activity - advisory, publication, investigation - on behalf of the MD as healthy, traditional, sustainable or representative of a community or region. The staff of the MDF consists of professionals with academic training in social anthropology, marketing and nutrition. The MDF maintains both a scientific secretariat, located in the Barcelona science park, and a scientific committee. The MDF arranges for those scholars they are interested in to be published. For instance, it financed the translation and re-edition in Spanish of the book "How to Eat Well and Stay Well. The Mediterranean Way" by Dr. Ancel Keys (1975). Results of research promoted by the MDF prove that the MD is healthy, sustainable and traditional or authentic.

The MDF return to the scholars publishing, honoring, financing, as well as presenting their activities in meetings and congresses. "In 1996 with the patronage of the Mayor of Barcelona, the 1st International Congress on the Mediterranean Diet released the Barcelona Declaration on the Mediterranean Diet" (Reguant-Aleix et al. 2009, 1591). Since then, the MDF has bi-annually granted personalities from the scientific sphere with the Grande Covián Prize. The scholars presented with this prize, have done research on the medical benefits of the MD. The scientific advisors of the MDF are principally experts in the medical-clinical-nutritional field. Since 1996, the MDF has organized an MD congress bi-annually in Barcelona on "the impact of dietary habits on health and the influence of history and culture on food in the Mediterranean" to which scholars from different disciplines are invited (as of December 13, 2013, on the web of the MDF). The confluence of economic, scientific and political institutions and experts within the MDF finds in this congress a privileged stage. In 2012 for example, the congress was celebrated within the International Food and Beverage Exhibition, Alimentaria, taking place at the Alimentaria Hub, "a great interconnecting center for innovation, knowledge and trends for the food industry and stakeholders." Another example is the Gallina Blanca Health and Nutrition Days: The MDF and Spanish state television collaborate with the event under the motto "Food is life". 


\section{The uses of gastronomic heritage}

In the previous two sections we have seen how the MD is discursively constituted and institutionally promoted in Spain. The outcome of this agency-driven social process is the MD, a cultural heritage that now is different to other gastronomic practices: Qualitatively because its sustainable, ecological and healthy food. Culturally, because its Mediterranean, traditional and authentic. This section now reflects on how this difference may be capitalized, disputed and appropriated in contemporary Spain.

The food industry is the most important industrial sector in Spain, in terms of volume of trade and percentage of GNP. It occupies fifth place in total volume within Europe as the Spanish Federation of Alimentation and Beverage Industries announces on its web (fiab.es). All typically Spanish agricultural food products such as vegetables, cereals, citrus fruits, wine, and olive oil are considered part of the MD. In particular, intensive irrigation has led to the growing importance of fruit and vegetable exports (GómezLimón and Picazo-Tadeo 2012, 57). At the same time, Spain is the European country with the most land given over to ecological cultivation, which has taken off dramatically over recent years (Willer and Kilcher 2012, 26, 28). But also the gastronomic services strongly related to tourism should be appreciated as part of this economic pillar: "Gastronomy, heritage and tourism are old friends; the relationship between them is mutually parasitic" (Van Westering 1999, 75).

Specific food consumption practices are communicated throughout the heritage process as a Mediterranean lifestyle. Different touristic goods and services can now be promoted as a traditional, authentic, and culturally sustainable. The linguist, Guy Cook, suggests that we can trace in the "language of food politics" how "individual choices [food preferences] are heavily influenced by language, as those with vested interests seek to persuade individuals to act in certain ways" $(2010,168)$. The discourse of food marketing is poetic, story-telling, sensual, related to health benefits, and refers more to emotion than to cognition (Cook 2010, 173-175). The MD as an ICH item of Humanity constitutes just such an moral-emotional, health-beneficial narrative.

Spanish cuisine has grown in relevance as an economic sector over more or less the last ten years (Wong 2013). Spanish chefs and restaurants, which evidently use elements of the MD as a business model, play in the world's leading gastronomic league. According to the English magazine Restaurant, three of the top ten restaurants in the world in 2013 are located in Spain. The restaurant El Celler de Can Roca in Girona is in first place. Another international indicator for restaurant quality is the Michelin-stars-system, a haut cousin restaurant index published by the company Michelin, measuring restaurants from zero (less) to three stars (most). On August 16, 2011, the Huffington Post published the fact that San Sebastian is the second most Michelin-starred city in the world in relation to the number of inhabitants. The gourmet market in Spain is 
principally a tourism resource; more than 80 per cent of three-star Michelin restaurant visitors are foreigners (El País, August 26, 2012). It is not hard to imagine that all the companies and professional associations related to this business field welcome the fact that their products and services may be communicated as an ICH item of Humanity. Publicity, added value, new products and clients can be expected. At the beginning of 2014 the restaurant DiverXo in Madrid was awarded three stars by Michelin. One of its famous dishes is called fried Mediterranean prawns with yuzu and hot mayonnaise ( $E l$ País, November 22, 2013). For instance, the MDF, together with the health department of the government of Catalonia, has encouraged the AMED project in order to promote the Mediterranean diet in restaurants.

As social capital, the MD is a platform for linking elites from the economic, scientific and political spheres through meetings, institutions, congresses, working groups, etc. The MD as an ICH item of Humanity is a catalyzer for communication between different social systems, which strengthens synergies, and articulates conflicts. In particular, in the contemporary Spanish political arena, central and regional governments compete for grades of nationalist autonomy, fomenting the cultural difference between the Mediterranean and non-Mediterranean people through encouraging for example, gastronomic singularities, related discourses and practices potentially exploitable for merging cultural and political borders. The MD as a proposal encouraged by southern European state parties and the technical coordination by the MDF rooted in Catalonia illustrates the possibility for political appropriation of ICH items of Humanity through actors from below and beyond the nation state. The Mediterranean sphere can be claimed both as a proper transnational entity as well as a particularity of a region inside a nation state. In this sense it is significant that the Andalusian and the Catalonian administration have established institutions which articulate the specific regional interests in the Mediterranean sphere in general and also specifically related to the MD. Andalusia shaped the European Institute for Mediterranean alimentation while Catalonia encouraged the European Institute of the Mediterranean in 1989. While the MDF is supported by the Catalonian government, the Juan Ramón Guillén foundation, located in Andalusia, states on its website that their "main goal is to declare the Andalusian olive grove as world cultural heritage". Maybe we can establish a relation between the unrepresented olive oil industry in the MDF and the different economic and political heritage agendas of the regions of Catalonia and Andalusia? While, for instance, olive oil or the Mediterranean stand for Spain or/and southern Europe, inside Spain these items may represent an economic and cultural north-south dichotomy. We might say that the MD is a powerful symbol in this respect, because it simultaneously evokes various positively-charged cultural markers, like warm climate, landscapes, food, tradition, lifestyle, health, etc.

Related to UNESCO's ICH List admission requirements, the role of politics, from the local to the global, is fundamental. Cultural elements aspiring to admittance need to be included in the corresponding national inventory. But, at the same time, UNESCO emphasizes that the community is the basic unit representing the cultural element. 
Communities therefore can not avoid the nation state as promoter of their heritage and vice-versa. Additionally, the MD is promoted by various nation states. Transnational entities (southern Europe or the Mediterranean countries) nation states (Spain), autonomous regions (Catalonia), and communities (Soria) both compete and collaborate through heritage entrepreneurs like the MDF. At the time, all of them may claim the element as theirs for political purposes on different political stages.

Symbolically, a close association of professional activity related to the ICH List and ICH items of Humanity proportions international visibility. Thus, the UN, the catalogue label and the specific element in question is related to universal and hegemonic moral frameworks. These being in our case, for example, intercultural dialogue or healthy, socially and environmentally friendly agro products. In addition, the global approach of the UN serves to spread awareness of the local heritage item beyond the habitual spheres of influence of scientific, economic or political activity related to it. These global moral frameworks are best summarized on the principal webpage of the MDF, giving people, things and ideas related to the MD a social, symbolic and economic relevance:

A lifestyle. Scientists have shown that this lifestyle is beneficial to health and welfare of people. It contributes to the maintenance of sustainable agriculture and protects the environment. (MDF website, December 13, 2013)

Different scientific disciplines find in the MD a field for research. This paper itself provides evidence of this. Direct or indirect scientific participation in the heritage construction process has a series of benefits for the scholars as there may be international reputation, political and economic promotion and financing of research, possibilities for specialization and institutionalization of the researchers' area of interest. The previously discussed socioeconomic implications of cultural heritage have a structural relation with the scientific field. Two principal discourses constitute the academic resource MD: a medical-nutritional and an anthropological-cultural. As UNESCO's ICH definition requires an ethnic foundation, in the nomination file for the MD there are various quotes on anthropological- ethnological studies on Mediterranean alimentation (Contreras, Riera, and Medina 2005; Cresta and Teti 1998; Garine 1997; Lupton 1994). Specifically, a research design focalized on why the MD is or should be an ICH item of Humanity and an enquiry into the strictly positive aspects of the products, people, places, activities related to this food is mainly the content of such academic activity. Direct institutional links between academics can be addressed to socio-anthropological publications such as "Flavors of the Mediterranean. Contributions to promote a common alimentary heritage" directed by Contreras, Riera, and Medina (2005; translation is mine). The book is edited by the European Institute of the Mediterranean promoted by the Catalonian administration. 


\section{Conclusions}

In the first paragraph of our conclusions we want to discuss the acknowledged limitations and scope of our contribution. Our approach does not attempt to give the only valid interpretation of the MD as a contemporary heritage process. Our theoretical framework takes multiple layers of social reality as a given. Different approximations to our case, for example through qualitative fieldwork within the community of Soria and its local social organization, may have added a different, more participative view of the MD and its relation to the community. Therefore, we do not reject the legitimacy of a universalist approach to ICH as encouraged by the UNESCO ICH List and the MD promoters, nor do we argue that heritage construction processes are out of the community's control. It is the relation between the global and the local institutions that should be described for every specific case of ICH items of Humanity in terms of legitimization, appropriation, conflict, synergy, confluence, exchange, contradiction, etc. For our case, we decided to take a closer look at the uses of the community and of moral frameworks by global and national players without discarding the existence of local compensations, benefits, or counter-narratives. Therefore we agree with the anthropologist Thomas H. Erikson who criticizes UNESCO's naïve notion of culture, but, nevertheless, says that the shortcomings, self-contradictions and the need for compromise in the efforts of UNESCO "cannot be easily resolved in theory nor in practice. Traditionalism and modernism, ethnic fragmentation and global unification are complementary dimensions of political processes in the contemporary world" (2001, 136). Our case may not be representative of all the approximately three hundred elements on the ICH List. Nevertheless, it can shed light on a specific dimension within all these items. We measured this dimension in terms of heritage entrepreneurship in order to test the validity of agency-driven understanding of the heritage process.

Additionally, our approach does not attempt to substitute or delegitimize enquiries focused on what heritage is, e.g. why some people consume olive oil and others do not, or why it is an important food element in relation to social and cultural organization. Our decision to focus on what is done with heritage is inspired by an anthropological approach and from the empirical evidence of our case study. At the same time, we include science, and therefore our own contribution to the analysis. We do so when we comment on anthropological and medical research related to the MD and when we reflect both on critical and legitimizing academic discourses as a part of the heritage construction process. We recognize the role of academics with their specific interests within the social constitution of ICH items of Humanity. A scientific approach, revealing commonly less perceived social logics, is a reflexive motivation, normally cultivated in university environments.

We suggested that heritage could be considered a capital in Pierre Bourdieu's sense of the term (Bourdieu 1983; Canclini 1999, 18; Velasco 2012). Cultural elements have an associated symbolical, material and social value. Heritage construction processes foster the specific value of cultural elements. This added value takes the element into a 
contested arena, where various social agents compete for the benefits associated with heritage. It's value can be created, appropriated, exploited and promoted by different agents within a social field. Once we assume a heritage concept as socially constructed the focus of our research necessarily changes from what it $i s$ to from whom and how is it created. The socio-historical process of consolidation of a cultural element as an ICH item of Humanity has to be related to different social groups actively implicated in this emergence and consolidation.

The case of the MDF shows that heritage construction processes and their exploitation can be addressed to specific institutions. Heritage entrepreneurship is presented as a public-private partnership of experts appropriating cultural elements to be used in both the global and local economic, scientific and political market. This hybrid administration-business laboratory, with its supporters, staff and activities is a metaphor for the functionally differentiated society's relationship with cultural heritage. The importance of the role of experts, the constructivist character of a mediated reality, the contradiction of local culture and identity as a global values and the confluence of political, economic and scientific power are some of the main results we may appreciate within our case. Employing an anthropological entrepreneurship concept has led our enquiry to focus on the institutionalizing processes linked to particular agents and interests. Consequently, the idea of heritage construction and exploitation as a resource for elites emerges. Because of the commonly held view of entrepreneurship as business creation at a micro-social level, we suggest that our unusual employment of the term produces a fruitful questioning of previously accepted perspectives. We suggest a productive line for future inquiry would be comparing this case with other heritage elements, heritage entrepreneurs and their social logics. This may reveal differences and similarities and prove the strength of our heritage entrepreneurship model.

Cultural heritage was once considered the symbolic expression of every era's elites. The exclusivist monumentalistic, historical and esthetic criteria for identifying cultural heritage indicates its tendency to represent the dominant class. This idea has been substituted by a democratic, plural concept of cultural heritage. The most important idea in this consensus-driven notion of cultural heritage, as encouraged in the 2003 Convention, is that it represents communities and societies, not only dominant groups within these communities and societies. Furthermore, the active implication of the whole of civil society should be guaranteed. This romantic idea of heritage as belonging to popular living culture and ethnic identities is strongly promoted by UNESCO. We sustain that this new ethnically justified cultural heritage discourse is directly linked to globalization. We suggest that an ICH item of Humanity merges culture into a powerful communication instrument created, managed and expanded by heritage entrepreneurs in a global society, where power, both on a global and local level, seeks to connect with new imperative values such as health and nutrition, local cultural identity or ecology. Finally, we state that ICH items of Humanity such as the MD provide synergies for different functional systems. The complementary relationship between ethnic identity discourse (exploited politically), the nutritional-environmental discourse (exploited 
economically), and the heritage discourse itself (exploited academically) in the case of the MD illustrates this confluence of purposes.

\section{Acknowledgements}

I would like to thank both the anonymous reviewers of the journal and Ray Harte for their corrections and discussions improving form, argument and understanding of the final version of the text.

\section{References}

Appadurai, Arjun. 1981. The Past as a Scarce Resource. Man, New Series 16 (2): 201219.

Bourdieu, P. [1972] 2000. Esquisse d'une théorie de la pratique, précédé detrois études d'ethnologie kabyle. Paris: Seuil.

Bourdieu, P. 1980. Le sens pratique. Paris: Éditions de minuit.

Bourdieu, P. 1983. “Ökonomisches Kapital, kulturelles Kapital, soziales Kapital.” Soziale Ungleichheiten. Soziale Welt Sonderheft 2: 183-198.

Brumann, Christoph. 2011. "Unser aller Kulturgut: Eine ethnologische Annäherung an das UNESCO-Welterbe.” Sociologus 61: 19-44.

Contreras, J., A. Riera, and X. Medina. 2005. Sabores del Mediterráneo. Aportaciones para promover un patrimonio alimentario común. Barcelona: IEMed.

Cook, Guy. 2010. "Sweet talking: Food, language, and democracy." Language Teaching 43 (2): 168-181.

Cresta, M. and V. Teti. 1998. "The Road of Food Habits in the Mediterranean Area". Rivista di Antropología 76: supplement.

Crooke, Elizabeth. 2010. "The politics of community heritage: motivations, authority and control.” International Journal of Heritage Studies 16 (1-2): 16-29.

De Bruin, Anne. 2003. "Indigenous entrepreneurship.” In: Entrepreneurship: New Perspectives in a Global Age, edited by Anne De Bruin, and Ann Dupuis, 169-184. Burlington: Ashgate Publishing.

Eriksen, Thomas Hylland. 2001. "Between universalism and relativism: A critique of the UNESCO concepts of culture.” In: Culture and Rights: Anthropological Perspectives, edited by J. Cowan, M. B. Dembour, and R. Wilson, 127-148. Cambridge: University Press. 
EU (European Union). 2006. "2006/144/EC: Council Decision of 20 February 2006 on Community strategic guidelines for rural development (programming period 2007 to 2013)." Official Journal of the European Union.

García Canclini, Néstor. 1999. "Los usos sociales del Patrimonio Cultural." In: Patrimonio Etnológico. Nuevas perspectivas de estudio, edited by E. Aguilar Criado, 16-33. Sevilla: Junta de Andalucía.

Garine, I. 1997. “Alimentación méditerranéenne et réalité”. In: Antropología de la Alimentación: nuevos ensayos sobre la Dieta Mediterránea, edited by I. González Turmo and P. Romero de Solís. Sevilla: Fundación Machado.

Gómez-Limón, J. and A. Picazo-Tadeo. 2012. "Irrigated Agriculture in Spain: Diagnosis and Prescriptions for Improved Governance". International Journal of Water Resources Development 28 (1): 57-72.

Harvey, David C. 2001. "Heritage Pasts and Heritage Presents: temporality, meaning and the scope of heritage studies." International Journal of Heritage Studies 7 (4): 319338.

Hobsbawm, E. J., and T. O Ranger. [1983] 2012. The Invention of Tradition. Cambridge, UK; New York: Cambridge University Press.

Keys Ancel, and Margaret Keys. 1975. How to eat well and stay well the Mediterranean way. New York: Doubleday.

Kirshenblatt-Gimblett, B. 2004. "Intangible Heritage as Metacultural Production." Museum International 56: 52-65.

Luhmann, N. [1984] 1987. Soziale Systeme. Grundriss einer allgemeinen Theorie. Frankfurt a. M.: Suhrkamp.

Luhmann, N. [1997] 2007. La sociedad de la sociedad. México D. F.: Herder.

Lupton, Deborah. 1994. "Food, Memory and Meaning: The Symbolic and Social Nature of Food Events". The Sociological Review 42 (4): 665-685.

MDF (Mediterranean Diet Foundation). 2008. "Accreditation form of the MDF to be accredited to provide advisory services to the committee. NGO 90021." Accessed May 2. http://www.unesco.org/culture/ich/index.php?lg=en\&pg=00329

Pfeilstetter, R. 2011. "El emprendedor. Una reflexión crítica sobre usos y significados actuales de un concepto." Gazeta de Antropología 27 (1): article 16. http://hdl.handle.net/10481/15684.

Pfeilstetter, R. 2012. Bourdieu y Luhmann: Diferencias, similitudes, sinergias. Revista Internacional de Sociología 70 (3): 489-510. 
Pfeilstetter, R. 2013. "Entrepreneurship and regional development in Europe. A comparative, socio-anthropological case study in Germany and Spain". Anthropological notebooks 19 (1): 45-57.

Prott, Lyndel V. 2009. "UNESCO international framework for the protection of the cultural heritage." In: Cultural heritage issues: The legacy of conquest, colonization, and commerce, edited by J. A. Nafziger, and A. M. Nicgorski, 257-280. Leiden: Martinus Nijhoff.

Reguant-Aleix, J., M. R. Arbore, A. Bach-Faig, and L. Serra-Majem. 2009. "Mediterranean Heritage: an intangible cultural heritage." Public Health Nutrition 12(9A): 1591-1594

Silverman, Helaine (ed.). 2011a. Contested Cultural Heritage. Religion, Nationalism, Erasure, and Exclusion in a Global World. New York: Springer.

Silverman, Helaine. 2011b. "Contested Cultural Heritage. A Selective Historiography." In: Contested Cultural Heritage. Religion, Nationalism, Erasure, and Exclusion in a Global World, edited by H. Silverman, 1-49. New York: Springer.

Smith, Laurajane. 2006. Uses of Heritage. London: Routledge.

UNESCO. 2003. Convention for the Safeguarding of Intangible Cultural Heritage.

UNESCO. 2010a. "Accreditation of non-governmental organizations to act in an advisory capacity to the Committee. Draft Resolution ITH/10/3.GA/CONF.201/7." Accessed May 2. http://www.unesco.org/culture/ich/index.php?pg=00283\&lg=en

UNESCO. 2010b. "Nomination file no. 00394 for the inscription on the UNESCO Representative List of the Intangible Cultural Heritage of Humanity.” Nairobi, Kenya.

UNESCO. 2012. Operational Directives for the Implementation of the Convention for the Safeguarding of the Intangible Cultural Heritage.

UNESCO. 2013. "Nomination file no. 00884 for inscription on the UNESCO Representative List of the Intangible Cultural Heritage of Humanity." Baku, Azerbaijan.

UNWTO (United Nations World Tourism Organization). 2013. "Tourism Highlights 2013 Edition." Accessed December 12. http://mkt.unwto.org/publication/unwtotourism-highlights-2013-edition

Van Westering, Jetske. 1999. "Heritage and gastronomy: The pursuits of the "new tourist'.” International Journal of Heritage Studies 5 (2): 75-81.

Velasco Maillo, Honorio M. 2012. De patrimonios culturales y sus categorías. Gazeta de Antropología 28 (3): article 13. http://hdl.handle.net/10481/23343 
Wang, Ning. 1999. "Rethinking authenticity in tourism experience." Annals of Tourism Research 26 (2): 349-370.

Watertona, E., L. Smith, and G. Campbella. 2006. "The Utility of Discourse Analysis to Heritage Studies: The Burra Charter and Social Inclusion”. International Journal of Heritage Studies 12 (4): 339-355.

Willer, H., and L. Kilcher. 2012. The world of organic agriculture. statistics and emerging trends 2012. Frick: FiBL.

Wong, Hiufu. 2013. "Spanish cuisine: Best food in the world right now?" CNN Travel, April 19. http://travel.cnn.com/spanish-food-trend-689636.

Zamora Acosta, Elías. 2011. "Sobre Patrimonio y Desarrollo. Aproximación al Concepto de Patrimono Cultural y su Utilización en Procesos de Desarrollo Territorial." Pasos: Revista de Turismo y Patrimonio Cultural 9 (1): 101-113.

Zuckin, Sharon. 2008. "Consuming authenticity.” Cultural Studies 22 (5): 724-748. 